\title{
Long-term study of smoking by secondary schoolchildren
}

\author{
M. H. BANKS, B. R. BEWLEY, J. M. BLAND, J. R. DEAN, AND V. POLLARD \\ From the Department of Community Medicine, St Thomas's Hospital Medical School and Department of \\ Clinical Epidemiology and Social Medicine, St George's Hospital Medical School, London; and \\ Nottingham Area Health Authority (Teaching), Mansfield, Nottingham
}

SUMMARY We report the methodology and some first year results of a 5-year longitudinal study of smoking. In 6330 Derbyshire secondary schoolchildren aged 11-16 years, $6 \%$ of boys and $2 \cdot 5 \%$ of girls were smoking one or more cigarettes per week. Higher rates of regular smoking and of children who had tried smoking were found in secondary modern schools, followed by middle, comprehensive, and grammar schools. The results clarify the relationship between children's smoking habits and those of the parents and siblings. Boys were more likely to smoke if their fathers smoked and girls were more likely to smoke if their mothers smoked. Irrespective of parental smoking, whether or not siblings smoked had a great influence on whether the child would smoke. Having more money to spend, working at a part-time job, spending more evenings out with a mixed-sex peer group, at a youth club, or out dancing, and playing truant from school were all associated with an increased risk of smoking.

The widespread use of cigarettes among adolescents, with its associated health hazards, has caused concern in a number of reports (US Surgeon-General, 1964; Royal College of Physicians, 1971; World Health Organization, 1975). Effective antismoking health education is hampered by a lack of understanding of why children start to smoke. We here describe the methodology of a longitudinal study over 5 years of 6330 Derbyshire schoolchildren aged 11-16 and present some findings from the first year. The aims of the study were: (i) to provide prevalence and incidence figures for smoking in a school population of boys and girls aged 11-16 years; (ii) to assess the effect of smoking on the respiratory symptoms of a defined population of schoolchildren; (iii) to investigate some of the environmental, social, and psychological factors that are associated with the recruitment of smokers and the maintenance of the smoking habit; (iv) to evaluate antismoking programmes for schoolchildren.

\section{Methods}

The study is still being carried out in Derbyshire on four groups of schoolchildren. Table 1 shows the design of the study. Schools were chosen to provide approximately 7000 children in the prospective group

Received 9 May 1977
Table 1 MRC/Derbyshire longitudinal smoking study: design of study

\begin{tabular}{|c|c|c|c|c|c|}
\hline & \multicolumn{5}{|c|}{ Years of study } \\
\hline & 1974 & 1975 & 1976 & 1977 & 1978 \\
\hline \multicolumn{6}{|l|}{ Age of pupils $(y r)$} \\
\hline $\begin{array}{l}11 / 12 \\
12 / 13\end{array}$ & $x$ & $\mathbf{X}$ & & $\mathbf{S}$ & \\
\hline $13 / 14$ & & & $\mathrm{X}$ & & \\
\hline $14 / 15$ & $\mathbf{S}$ & & & $\mathrm{X}$ & \\
\hline $15 / 16$ & & & & & $\mathbf{X}$ \\
\hline Parents & Px & & & & Px \\
\hline Teachers & $\mathbf{T}$ & $\mathbf{T}$ & & & $\mathbf{T}$ \\
\hline \multicolumn{2}{|l|}{$\begin{array}{l}\text { Controls (Hawthorne) } \\
15 / 16 \text { years old }\end{array}$} & & & & $\mathbf{H}$ \\
\hline Int & \multicolumn{5}{|c|}{ Anti-smoking programme evaluation } \\
\hline
\end{tabular}

$\mathrm{X}=$ prospective group children; $\mathrm{S}=$ secular trend group;

$\mathbf{P x}=$ parents of prospective group; $\mathrm{T}=$ teachers in prospective group schools; $\mathbf{H}=$ Hawthorne group.

and approximately 2500 children in each of the other groups. These numbers were chosen so that subgroups of smokers and nonsmokers would be large enough to allow for comparisons.

(i) The prospective group children will have been studied from 1974 to 1978 , that is from the age of $11 / 12$ years and in their first year of secondary school to age 15-16 years. (ii) The secular trend group were incorporated into the study in order to see what 
changes in smoking habits, if any, occur with time, independent of age. Children from a subsample of the prospective group schools (2500 14-15 year olds) were asked in 1974 about their smoking habits. In a similar manner, 2500 11-12 year olds from the same schools were asked in 1977 about their smoking habits. (iii) The Hawthorne group consists of 2500 children aged 11-12 years in 1974, who will not be asked to participate until 1978. The reason for this is to assess the experimenter effect upon behaviour of people being studied (Roethlisberger and Dickson, 1939). Repeated questioning of a group of children about smoking may influence their smoking behaviour. (iv) A group was also selected for the purpose of evaluating the effects upon smoking habits of antismoking programmes.

The parents of the prospective group children completed questionnaires in the first year of the study. Teachers in the prospective group schools completed a short, anonymous questionnaire in the first 2 years of the study. Parent and teacher questionnaires will be repeated in 1978, the last year of the study. All questionnaires are self-administered and self-coded.

The sampling frame consisted of all state secondary schools in the county of Derbyshire. In cases where the age of school entry was more than 11 years, the middle school(s) that was linked to the secondary school was included with the secondary school as one sampling unit.

In defining the prospective group, Hawthorne, and intervention groups, the schools in the sampling frame were divided into three strata: the urban/rural definition was that used by Derbyshire Education Committee, namely (a) schools in Derby, (b) schools in urban areas outside Derby, (c) rural and mixed rural/urban schools.

For each stratum the total yearly intake was calculated and schools were allocated at random to the three sampling groups by putting a school into the Hawthorne group, a school into the intervention group, and three schools into the prospective group. A 'running total' of the children in each group was kept until the required number of children had been assigned to a group, and then no more schools were allocated to it. The required numbers were 7000 in the prospective group, and 2500 each to the Hawthorne and intervention groups. Schools for the secular trend group were selected from among the prospective group by calculating the number of children in each stratum required to give an intake of 2500 or erall and then choosing the schools at random until the necessary total of children was reached. In some cases two or more schools were combined into one sampling unit because there was either interchange of pupils or an intention to amalgamate the schools.
The largest such group was the Chesterfield schools, where children could move to either of two senior schools at age 13 plus, and therefore all schools in Chesterfield were included in the sampling frame as one unit. The two largest urban areas in the county, Derby and Chesterfield, account for $45 \%$ of the secondary schools in the prospective sample. The remaining schools are located in rural areas and in so-called 'industrial villages', many of them mining communities to the east of the county. When sampling was completed, the prospective group consisted of 51 schools and 7383 children aged 11-12 years in 1974.

In the spring of 1974 all schools in the sample were visited by a research worker (M.H.B. or B.R.B.) to explain the project to the headteacher and request co-operation. Three headteachers refused to participate. During these visits a questionnaire requesting information about the school was completed. All schools arranged for the self-administered children's questionnaires to be completed in classrooms within one week in June 1974. The teachers completed their questionnaires at the same time.

In September 1974 the parents' questionnaires were mailed to home addresses, and replies were returned in pre-paid envelopes. Nonresponders were contacted by post on two subsequent occasions. The remaining nonresponders were contacted at home by a team of trained interviewers.

At the end of the first year, out of 7383 children eligible to take part in the survey, 6330 (3098 boys and 3232 girls) had completed questionnaires, a response rate of $85.7 \%$, with $1.5 \%$ refusals and $12 \cdot 8 \%$ absentees.

\section{Results}

Smoking prevalence rate (Table 2). Children's smoking was classified by means of the answers to the following five statements, to which they were asked to give one reply: I have never smoked a cigarette; I have only ever tried smoking once; I have smoked sometimes, but I don't smoke as much

Table 2 Smoking prevalence rates (1974, children aged $11 / 12$ years old)

\begin{tabular}{|c|c|c|c|c|}
\hline Classificatic & ion by smoking experience & $\begin{array}{l}\text { Boys } \\
(\%)\end{array}$ & $\begin{array}{l}\text { Girls } \\
(\%)\end{array}$ & $\begin{array}{l}\text { Total } \\
(\%)\end{array}$ \\
\hline \multirow[t]{3}{*}{$\begin{array}{l}\text { Nonsmoker } \\
\text { tried }\end{array}$} & $\begin{array}{c}\text { Triers }\left\{\begin{array}{l}\text { Never smoked } \\
\text { Tried smoking once } \\
\text { Smoke }<1 \text { per week }\end{array}\right. \\
\text { Smokers }\left\{\begin{array}{l}\text { Smoke } 1-6 \text { per week } \\
\text { Smoke }>6 \text { per week } \\
\text { Not known }\end{array}\right.\end{array}$ & $\begin{array}{r}44 \cdot 9 \\
34 \cdot 6 \\
14 \cdot 1 \\
3 \cdot 1 \\
2 \cdot 9 \\
0 \cdot 4\end{array}$ & $\begin{array}{r}59 \cdot 8 \\
28.4 \\
9.1 \\
1.8 \\
0.7 \\
0.2\end{array}$ & $\begin{array}{r}52 \cdot 6 \\
31 \cdot 4 \\
11 \cdot 5 \\
2 \cdot 4 \\
1 \cdot 8 \\
0 \cdot 3\end{array}$ \\
\hline & & $100 \cdot 0$ & $100 \cdot 0$ & $100 \cdot 0$ \\
\hline & Base numbers & 3098 & 3232 & 6330 \\
\hline
\end{tabular}


as 1 a week; I usually smoke between 1 and 6 cigarettes a week; I usually smoke more than 6 cigarettes a week. The percentage of boys and girls who responded to each of these statements is given in Table 2.

The smoking prevalence rates for each of the 48 schools were analysed by each of the school characteristics (Appendix). Although there was wide variation between the schools in the proportion of children who said they smoked more than 1 cigarette per week (from $2 \%$ to $32 \%$ ), there were no clear major associations between these school characteristics and smoking prevalence rates, except that there were differences between the four types of schools. Table 3 shows that the highest rate of regular smokers and children who had tried smoking was found in secondary modern schools, followed by middle, comprehensive, and grammar schools.

Smoking by parents, siblings, and friends. The results of the question on parental smoking are given in Table 4. Both boys and girls were more likely to smoke if either of their parents smoked cigarettes. The relative risk if the father smoked was higher for boys and if the mother smoked it was higher for girls. Smoking prevalence was higher among boys with no father and among girls with no mother.

The results of siblings' smoking behaviour are given in Table 5. Boys and girls were more likely to have smoked if they had brothers or sisters than those who did not. This risk was accounted for by the number of siblings who smoked, as there was no diff-

Table 3 Smoking prevalence rates by type of school

\begin{tabular}{|c|c|c|c|c|c|c|c|c|c|}
\hline & \multicolumn{9}{|c|}{ Type of school } \\
\hline & \multicolumn{2}{|c|}{ Middle } & \multicolumn{2}{|c|}{ Secondary modern } & \multicolumn{2}{|c|}{ Grammar } & \multicolumn{2}{|c|}{ Comprehensive } & $\begin{array}{l}\text { Total } \\
(\%)\end{array}$ \\
\hline $\begin{array}{l}\text { Nonsmoker } \\
\text { Triers } \\
\text { Smoker } \\
\text { Not known }\end{array}$ & $\begin{array}{c}45 \cdot 4 \\
49 \cdot 6 \\
5 \cdot 0 \\
0\end{array}$ & $\begin{array}{c}59 \cdot 6 \\
38 \cdot 2 \\
2 \cdot 2 \\
0\end{array}$ & $\begin{array}{r}37 \cdot 0 \\
53 \cdot 5 \\
8 \cdot 8 \\
0 \cdot 7\end{array}$ & $\begin{array}{r}51 \cdot 0 \\
44 \cdot 8 \\
3 \cdot 8 \\
0.4\end{array}$ & $\begin{array}{r}52 \cdot 9 \\
44 \cdot 2 \\
2 \cdot 6 \\
0 \cdot 3\end{array}$ & $\begin{array}{c}72 \cdot 1 \\
25 \cdot 8 \\
2 \cdot 1 \\
0\end{array}$ & $\begin{array}{r}46 \cdot 4 \\
47 \cdot 6 \\
5 \cdot 6 \\
0 \cdot 3\end{array}$ & $\begin{array}{r}61 \cdot 4 \\
36 \cdot 4 \\
2 \cdot 0 \\
0 \cdot 2\end{array}$ & $\begin{array}{r}52 \cdot 6 \\
42 \cdot 9 \\
4 \cdot 2 \\
0 \cdot 3\end{array}$ \\
\hline$\%$ & 100 & 100 & 100 & 100 & 100 & 100 & $99 \cdot 9$ & 100 & 100 \\
\hline $\begin{array}{l}\text { Base number } \\
\text { Schools } \\
\text { Children }\end{array}$ & $\begin{array}{r}3 \\
220\end{array}$ & $\begin{array}{r}3 \\
183\end{array}$ & $\begin{array}{r}14 \\
705\end{array}$ & $\begin{array}{r}17 \\
835\end{array}$ & $\begin{array}{r}5 \\
342\end{array}$ & $\begin{array}{r}6 \\
384\end{array}$ & $\begin{array}{r}19 \\
1831\end{array}$ & $\begin{array}{r}19 \\
1830\end{array}$ & $\begin{array}{r}48 \\
6330\end{array}$ \\
\hline
\end{tabular}

Table 4 Parents' smoking

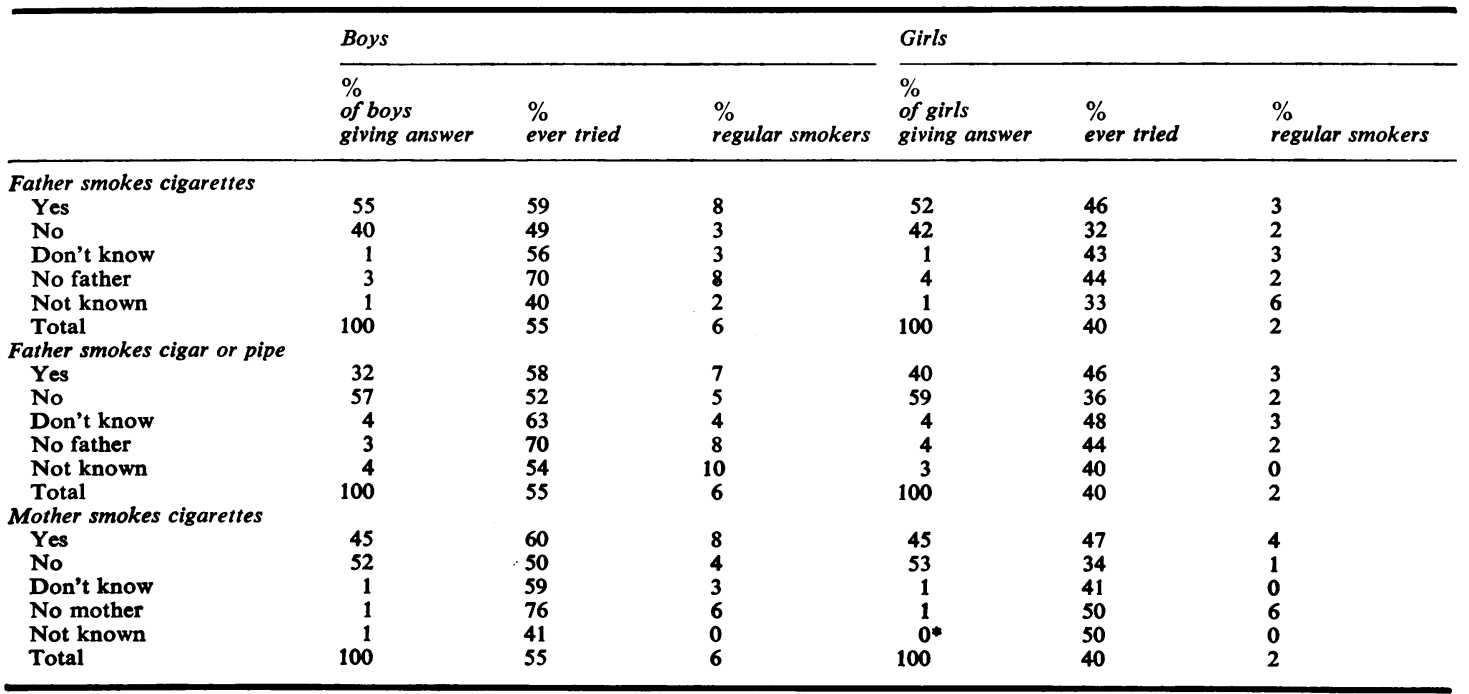

$\bullet 0 \%=10$ girls. 
Table 5 Brothers' and sisters' smoking

\begin{tabular}{|c|c|c|c|c|c|c|}
\hline & \multicolumn{3}{|l|}{ Boys } & \multicolumn{3}{|l|}{ Girls } \\
\hline & $\begin{array}{l}\% \\
\text { of boys } \\
\text { giving answer }\end{array}$ & $\begin{array}{l}\% \\
\text { ever tried }\end{array}$ & $\begin{array}{l}\% \\
\text { regular } \\
\text { smokers }\end{array}$ & $\begin{array}{l}\% \\
\text { of girls } \\
\text { giving answer }\end{array}$ & $\begin{array}{l}\% \\
\text { ever tried }\end{array}$ & $\begin{array}{l}\% \\
\text { regular smokers }\end{array}$ \\
\hline \multicolumn{7}{|l|}{ No. of brothers } \\
\hline 0 & 32 & 48 & 4 & 31 & 32 & 1 \\
\hline 1 & 36 & 54 & 5 & 38 & 40 & 3 \\
\hline 2 & 19 & 61 & 8 & 18 & 47 & 3 \\
\hline $3+$ & 13 & 65 & 11 & 12 & 50 & 4 \\
\hline \multicolumn{7}{|l|}{ Brothers who smoke } \\
\hline 0 & 80 & 50 & 3 & 82 & 35 & 2 \\
\hline 1 & 14 & 72 & 13 & 12 & 61 & 5 \\
\hline 2 & 4 & 80 & 16 & 4 & 68 & 9 \\
\hline $3+$ & 2 & 80 & 35 & 2 & 64 & 5 \\
\hline No brothers & 32 & 48 & 4 & 31 & 32 & 1 \\
\hline At least one brother, all nonsmokers & 48 & 51 & 3 & 51 & 37 & 2 \\
\hline $\begin{array}{l}\text { At least one brother, } \\
\text { at least one of whom smokes }\end{array}$ & 20 & 74 & 16 & 18 & 63 & 6 \\
\hline \multicolumn{7}{|l|}{ No. of sisters } \\
\hline 0 & 33 & 49 & 4 & 32 & 36 & 2 \\
\hline 1 & 38 & 53 & 5 & 37 & 39 & 2 \\
\hline 2 & 17 & 61 & 8 & 18 & 46 & 2 \\
\hline $3+$ & 12 & 68 & 12 & 13 & 45 & 4 \\
\hline \multicolumn{7}{|l|}{ Sisters who smoke } \\
\hline 0 & 84 & 51 & 4 & 85 & 35 & 2 \\
\hline 1 & 12 & 72 & 13 & 10 & 63 & 6 \\
\hline 2 & 3 & 84 & 19 & 4 & 68 & 8 \\
\hline $3+$ & 1 & 77 & 26 & 1 & 76 & 16 \\
\hline \multirow{3}{*}{$\begin{array}{l}\text { No sisters } \\
\text { At least one sister, all nonsmokers } \\
\text { At least one sister, } \\
\text { at least one of whom smokes }\end{array}$} & 33 & 49 & 4 & 32 & 36 & 2 \\
\hline & 52 & 52 & 4 & 53 & 35 & 1 \\
\hline & 16 & 75 & 15 & 15 & 65 & 7 \\
\hline
\end{tabular}

erence between children with no siblings and children with siblings who did not smoke.

If parents affect the child's smoking, it may be that the smoking by siblings will be similarly affected. $15 \%$ of children with nonsmoking parents reported at least one sibling who was a smoker, whereas when one or both of the parents smoked $31 \%$ of children reported a sibling who was a smoker. Thus we would expect an association between child's and siblings' smoking due to the effect of the parents. The effect of parents and siblings both smoking is shown in Table 6 . The effect of siblings' smoking on both trying smoking and regular smoking by the children was great, whether or not the parents smoked. However, only $5 \%$ of all children reported a sibling who smoked when neither parent did, compared to $22 \%$ of all children with both a sibling and a parent who smoked; so there were few children for whom smoking by siblings only was an influence. Although the effect of a sibling who smoked was greater than that of a parent who smoked, the sibling who smoked is seldom present to produce this effect when neither parent smokes. When both a sibling and a parent were smokers, $16 \%$ of boys and $6 \%$ of girls were smokers, compared to $1 \%$ and $0.6 \%$ when neither parents nor siblings smoked.

When children were asked how many of their friends smoked cigarettes, over $80 \%$ of boys and girls said that few or none of their friends smoked, but children were more likely to have tried smoking if they had more friends who smoked. For example, of those boys who said all or most of their schoolfriends smoked, $84 \%$ had tried cigarettes; whereas of those boys who said few of their schoolfriends smoked, $51 \%$ had tried cigarettes. More boys than

Table 6 Relationship between parents' smoking, siblings' smoking, and the child's smoking

\begin{tabular}{|c|c|c|c|c|c|c|c|}
\hline \multirow[b]{2}{*}{ Parents' smoking } & \multirow[b]{2}{*}{ Siblings' smoking } & \multicolumn{3}{|c|}{ Boys' own smoking } & \multicolumn{3}{|c|}{ Girls' own smoking } \\
\hline & & $\boldsymbol{n}$ & $\begin{array}{l}\% \text { who } \\
\text { ever tried }\end{array}$ & $\begin{array}{l}\% \text { who } \\
\text { regularly smoke }\end{array}$ & $n$ & $\begin{array}{l}\% \text { who } \\
\text { ever tried }\end{array}$ & $\begin{array}{l}\% \text { who } \\
\text { regularly smoke }\end{array}$ \\
\hline $\begin{array}{l}\text { Neither smoke } \\
\text { One or both who smoke } \\
\text { Total }\end{array}$ & $\begin{array}{l}\text { No sibs who smoke } \\
\text { At least one sib who smokes } \\
\text { No sibs who smoke } \\
\text { At least one sib who smokes }\end{array}$ & $\begin{array}{r}699 \\
149 \\
1344 \\
653 \\
2845\end{array}$ & $\begin{array}{l}37 \\
73 \\
52 \\
74 \\
54\end{array}$ & $\begin{array}{r}1 \cdot 0 \\
10 \cdot 1 \\
3 \cdot 6 \\
15 \cdot 5 \\
6 \cdot 0\end{array}$ & $\begin{array}{r}813 \\
120 \\
1435 \\
617 \\
2985\end{array}$ & $\begin{array}{l}25 \\
51 \\
37 \\
64 \\
40\end{array}$ & $\begin{array}{l}0 \cdot 6 \\
5 \cdot 0 \\
1 \cdot 7 \\
6 \cdot 3 \\
2 \cdot 5\end{array}$ \\
\hline
\end{tabular}


girls who said none of their friends smoked had tried cigarettes.

Out-of-school activities, money, and part-time jobs. The frequencies of participation in spare-time activities are given in Table 7 . The best predictor of smoking and experimenting with cigarettes for both boys and girls was attending a youth club. Other predictors were going around with a group of their own age, and dancing, though few boys did the latter. The people with whom these out-of-school activities were shared also differentiated the smokers (Table 8), the most commonly reported being 'a friend', for both boys and girls. For boys, this was followed by 'a group of boys' and then 'parents'; for girls 'parents' followed by 'a group of girls'. Least common, and the best predictor of smoking were 'a group of girls' for boys, and 'a group of boys' for girls. The other good predictors for boys and girls were 'a boy- or girl-friend', and 'a group of boys and girls'. Thus, spending one's time with a peer group including the opposite sex was by far the highest risk factor.

Those children who spent more time doing homework had a lower risk of smoking, and conversely those who went out 5 or more evenings a week had an increased risk of smoking. Children who spent more than 50p a week had an increased risk of being smokers and of having tried cigarettes: this risk was greater for those who spent more than $£ 1$. Those who saved more than $£ 1$ were also more likely to be smokers than those who saved between $1 \mathrm{p}$ and $£ 1$. However, those who saved nothing also had an increased risk of smoking. The distribution of total disposable income by smoking habits is given in Table 9. There was a weak association between regular smoking and an income of nil, and a stronger association between regular smoking and an income of over $£ 1$ for both boys and girls. $44 \%$ of boys and $38 \%$ of girls had weekly incomes of over $50 \mathrm{p}$. Taking a part-time job outside school was associated with increased risk of smoking.

Truancy. Children were asked whether they played truant 'never', 'once or twice', 'sometimes', 'often'. Although only $2 \%$ of boys said they often played truant from school, $91 \%$ of these had tried smoking, as opposed to $82 \%$ of boys who said they never played truant, of whom $49 \%$ had tried smoking. The same association was found in the girls, and

Table 7 Spare time activities

\begin{tabular}{|c|c|c|c|c|c|c|}
\hline & \multicolumn{3}{|l|}{ Boys } & \multicolumn{3}{|l|}{ Girls } \\
\hline & $\begin{array}{l}\% \text { marking } \\
\text { YES to item }\end{array}$ & $\begin{array}{l}\% \\
\text { ever tried }\end{array}$ & $\begin{array}{l}\% \\
\text { regular smokers }\end{array}$ & $\begin{array}{l}\% \text { marking } \\
\text { YES to item }\end{array}$ & $\begin{array}{l}\% \\
\text { ever tried }\end{array}$ & $\begin{array}{l}\% \\
\text { regular smokers }\end{array}$ \\
\hline $\begin{array}{l}\text { Sports \& games } \\
\text { Cinema } \\
\text { Scouts or boys brigade } \\
\text { Guides or girls brigade } \\
\text { Music, hobby } \\
\text { Dancing } \\
\text { Go with group of own age } \\
\text { TV or records } \\
\text { Mess around } \\
\text { Youth club } \\
\text { Read } \\
\text { Help out at home house or farm } \\
\text { Total }\end{array}$ & $\begin{array}{r}75 \\
26 \\
15 \\
0 \\
46 \\
4 \\
43 \\
74 \\
57 \\
19 \\
38 \\
45 \\
100\end{array}$ & $\begin{array}{l}53 \\
63 \\
57 \\
54 \\
75 \\
65 \\
54 \\
60 \\
71 \\
47 \\
52 \\
55\end{array}$ & $\begin{array}{r}5 \\
7 \\
4 \\
5 \\
11 \\
10 \\
5 \\
8 \\
12 \\
3 \\
5 \\
6\end{array}$ & $\begin{array}{r}51 \\
18 \\
0 \\
18 \\
36 \\
22 \\
38 \\
78 \\
45 \\
20 \\
54 \\
62 \\
100\end{array}$ & $\begin{array}{l}39 \\
49 \\
35 \\
37 \\
46 \\
56 \\
39 \\
49 \\
57 \\
33 \\
37 \\
40\end{array}$ & $\begin{array}{l}2 \\
4 \\
2 \\
2 \\
4 \\
5 \\
2 \\
4 \\
6 \\
1 \\
2 \\
2\end{array}$ \\
\hline
\end{tabular}

Table 8 With whom spare time is spent

\begin{tabular}{|c|c|c|c|c|c|c|}
\hline & \multicolumn{3}{|l|}{ Boys } & \multicolumn{3}{|l|}{ Girls } \\
\hline & $\begin{array}{l}\% \text { marking } \\
Y E S \text { to item }\end{array}$ & $\begin{array}{l}\% \\
\text { ever tried }\end{array}$ & $\begin{array}{l}\% \\
\text { regular smokers }\end{array}$ & $\begin{array}{l}\% \text { marking } \\
Y E S \text { to item }\end{array}$ & $\begin{array}{l}\% \\
\text { ever tried }\end{array}$ & $\begin{array}{l}\% \\
\text { regular smokers }\end{array}$ \\
\hline $\begin{array}{l}\text { Group of boys } \\
\text { Group of girls } \\
\text { Boy- or girl-friend } \\
\text { A friend } \\
\text { Group of boys and girls } \\
\text { Parents } \\
\text { On my own } \\
\text { Don't go out much } \\
\text { Total }\end{array}$ & $\begin{array}{r}47 \\
3 \\
14 \\
53 \\
12 \\
23 \\
15 \\
8 \\
100\end{array}$ & $\begin{array}{l}60 \\
79 \\
73 \\
53 \\
72 \\
44 \\
48 \\
46 \\
55\end{array}$ & $\begin{array}{r}8 \\
23 \\
13 \\
4 \\
14 \\
3 \\
3 \\
2 \\
6\end{array}$ & $\begin{array}{r}6 \\
27 \\
13 \\
59 \\
19 \\
31 \\
15 \\
15 \\
100\end{array}$ & $\begin{array}{l}71 \\
48 \\
62 \\
40 \\
62 \\
27 \\
32 \\
32 \\
40\end{array}$ & $\begin{array}{r}13 \\
4 \\
8 \\
2 \\
7 \\
1 \\
3 \\
1 \\
2\end{array}$ \\
\hline
\end{tabular}


Table 9 Smoking by total disposable income/week

\begin{tabular}{|c|c|c|c|c|c|c|}
\hline \multirow[b]{2}{*}{ Income $(p)$} & \multicolumn{3}{|l|}{ Boys } & \multicolumn{3}{|l|}{ Girls } \\
\hline & $\begin{array}{l}\% \\
\text { giving answer }\end{array}$ & $\begin{array}{l}\% \\
\text { ever tried }\end{array}$ & $\begin{array}{l}\% \\
\text { regular smokers }\end{array}$ & $\begin{array}{l}\% \\
\text { giving answer }\end{array}$ & $\begin{array}{l}\% \\
\text { ever tried }\end{array}$ & $\begin{array}{l}\% \\
\text { regular smokers }\end{array}$ \\
\hline $\begin{array}{l}0 \\
1-10 \\
11-50 \\
51-100 \\
100+\end{array}$ & $\begin{array}{r}3 \\
2 \\
44 \\
24 \\
27\end{array}$ & $\begin{array}{l}55 \\
41 \\
50 \\
55 \\
65\end{array}$ & $\begin{array}{r}7 \\
5 \\
4 \\
4 \\
11\end{array}$ & $\begin{array}{r}3 \\
3 \\
50 \\
24 \\
20\end{array}$ & $\begin{array}{l}34 \\
27 \\
34 \\
44 \\
52\end{array}$ & $\begin{array}{l}4 \\
0 \\
1 \\
3 \\
5\end{array}$ \\
\hline
\end{tabular}

responses to 'playing truant often' was the best single predictor of smoking for both boys and girls in the questionnaire.

\section{Discussion}

Since prevalence studies of smoking in adolescents in the UK have been done on different populations at different times, comparison of findings is difficult and often speculative. Bewley et al. (1973) give a table of comparative prevalence rates in which they define a smoker as a child smoking 1 or more cigarettes a week. The results of our study show that $6 \%$ of boys and $2 \cdot 3 \%$ of girls aged $11-12$ years fall into this category. For boys this figure is comparable to previous findings. For example, Bothwell (1959) found $17 \%$ of 11 -year-old boys smoking, whereas Bynner (1969) found only $4 \%$ of the same age group to be smoking. Bewley and Bland (1976) found 7.6\% of a sample of 10- to 121 -year-old boys in Kent were smoking. There is no significant time trend in the prevalence figures quoted by Bewley et al. (1973), but nevertheless interpretation of this would be hazardous since different populations were sampled (the national sample of Bynner (1969) as compared with the regional sample of Bothwell (1959)). For the 11- to 12-year-old girls, the smoking prevalence rates have changed little over time and between different populations. We found $2.4 \%$ to be smoking 1 or more cigarettes per week. The comparable figures from earlier work are 2.4\% (Bothwell, 1959), $2.6 \%$ (Holland and Elliott, 1968), $1 \%$ (Todd, 1969), and $2.3 \%$ and $2.6 \%$ in two populations (Bewley and Bland, 1976). Although the same problems of sampling, methods of data collection, and year of study apply here, there nevertheless is greater uniformity between estimates of smoking among 11- to 12-yearold girls than between estimates of boys smoking at this age.

King (1973) and Hargreaves (1967) have reported on the influence of the school environment upon pupil behaviour. The school characteristics measured in this study were chosen after consideration of the work of these authors and so we expected that some of these characteristics would be associated with smoking prevalence rates. The finding that none of these characteristics was associated with smoking may be explained by the following points. Firstly, the children had been at the schools for less than a year and any profound effect that the school had upon their behaviour may not yet have made itself felt. Secondly, smoking prevalence rates in the final year of primary school (Bewley and Bland, 1976) were very similar to those of the first year of secondary school $(7.0 \%$ boys, $2.3 \%$ girls in primary school; $7 \cdot 6 \%$ boys, $2 \cdot 3 \%$ girls in secondary school; both estimates from a study in Kent), which means that for this small percentage of children who start smoking early influences are probably brought to bear before they reach secondary school.

The higher rates of smoking in secondary modern schools confirm the findings of Chave and Schilling (1959), Holland et al. (1969), and Bewley and Bland (1976). Since smoking prevalence rates of final year primary and first year secondary schoolchildren are similar, it appears that fewer of the smokers are selected at 11 years for grammar schools, and more of the children entering secondary modern schools had already started smoking.

Wohlford (1970) reported that male smokers generally identified with their fathers' smoking patterns (intact families) while 'mother and daughter smoking patterns remained enigmatic'. Our results confirm the association between the smoking of fathers and sons (Bewley et al., 1974) but they also show a similar association between mothers and daughters and between mothers and sons, which was also found by Bewley and Bland (1977). However, the influences of mother and father did not differ as much in the present study as in this earlier work. Furthermore, the relationship between the smoking patterns of parents, siblings, and the index children is now clarified: irrespective of parents' smoking, whether or not siblings smoked had a great influence on whether the index child smoked. Bynner (1969), in a survey of 11- to 15-year-old boys, found no association between parental and child smoking. Parental smoking may have a stronger influence in the younger age groups, which was clearly shown in our study, to be replaced by influences such as the peer group, as 
the child grows older. Further results from this longitudinal study should clarify this.

Carr (1963) suggested that the higher prevalence of smoking among inner city boys may be cxplained by the fact that part-time work is more available in the city centre, and the boys could consequently supplement their pocket money. The hypothesis has not been investigated further, but our results indicate that children who spend more money are more likely to smoke, as are children who take part-time jobs, and that either saving more than $£ 1$ per week or saving nothing was associated with an increased risk of smoking. Total disposable income was related to smoking in the same way. Those with more money were clearly more able to buy cigarettes, although those with no money had a slightly increased risk of smoking. Since cigarette consumption at this age is low, it is likely that cigarettes are passed around among friends.

Our results show that participation in out-ofschool activities is associated with smoking. Spending more evenings out, rather than doing homework, with a mixed-sex peer group, at a youth club, or dancing, are all related to an increased risk of smoking. As Sugarman (1967) suggested, a teenage culture exists outside of school which influences adolescent behaviour just as the school values also exert an influence. Part of this teenage culture indicates a rejection of the school, showing itself as truancy. Our results suggest that even at the age of 11-12 years these identifiable social forces have an influence on whether children begin to smoke or not. Perhaps the children most at risk of smoking are those who are immersed in the teenage out-of-school activities and who are, potentially, the hardest to reach using school-based health education.

We thank the children and teachers of the schools in the study for help and co-operation; Professor W. W. Holland, Dr A. H. Snaith, and Dr Kenneth Cartwright for help and support; the members and staff of Derbyshire Area Health Authority, in particular Mrs B. Baggett; Derbyshire Education Authority; members of the Department of Community Medicine, St Thomas's Hospital Medical School; and Juliet Chadwick for secretarial assistance.

This study is supported in part by a grant from the Medical Research Council and in part by the Department of Health and Social Security.

\section{References}

Bewley, B. R., and Bland, J. M. (1976). Smoking and respiratory symptoms in two groups of schoolchildren. Preventive Medicine, 5, 63-69.
Bewley, B. R., and Bland, J. M. (1977). Academic performance and social factors related to cigarette smoking by schoolchildren. British Journal of Preventive and Social Medicine, 31, 18-24.

Bewley, B. R., Day, I., and Ide, L. (1973). Smoking by

Children in Great Britain-a Review of the Literature. Social Science Research Council/Medical Research Council, London.

Bewley, B. R., Bland, J. M., and Harris, R. (1974). Factors associated with the start of cigarette smoking by primary schoolchildren. British Journal of Preventive and Social Medicine, 28, 37-44.

Bothwell, P. W. (1959). The epidemiology of cigarette smoking in rural choolchildren. Medical Officer, 102, 125-132.

Bynner, J. M. (1969). The Young Smoker. Government Social Survey. HMSO, London.

Carr, A. J. (1963). Smoking in teenage boys. Nursing Times, 59, 1093-1095.

Chave, S. P. W., and Schilling, R. S. F. (1959). The smoking habits of schoolchildren. British Journal of Preventive and Social Medicine, 13, 1-4.

Hargreaves, D. H. (1967). Social Relations in a Secondary School. Routledge and Kegan Paul, London.

Holland, W. W., and Elliott, A. (1968). Cigarette smoking, respiratory symptoms and anti-smoking propaganda. Lancet, 1, 41-43.

Holland, W. W., Halil, T., Bennett, A. E., and Elliott, A. (1969). Indications for measures to be taken in childhood to prevent chronic respiratory disease. Milbank Memorial Fund Quarterly, Vol. XLVII, No. 3, Part 2, 215-227.

King, R. (1973). School Organisation and Pupil Involvement. A Study of Secondary Schools. Routledge and Kegan Paul, London.

Roethlisberger, F. J., and Dickson, W. J. (1939). Management and the Worker. Harvard University Press, Cambridge, Mass.

Royal College of Physicians (1971). Smoking and Health Now. Pitman Medical, London.

Sugarman, B. (1967). Involvement in youth culture, academic achievement and conformity in school. British Journal of Sociology, 18, 151-164.

Todd, G. F. (1969). (Editor.) Statistics of Smoking in the United Kingdom, 5th ed. Tobacco Research Council, London.

U.S. Surgeon-General's Advisory Committee on Smoking and Health (1964). Smoking and Health. Public Health Service Publication No. 1103. US Department of Health, Education and Welfare, Washington.

Wohlford, R. (1970). Initiation of cigarette smoking: is it related to parental smoking behaviour? Journal of Consulting and Clinical Psychology, 34, 148-151.

World Health Organization (1975). Smoking and its Effects on Health. Report of a WHO Expert Committee. Technical Report Series No. 568. WHO, Geneva.

Correspondence to Mr M. H. Banks, Department of Community Medicine, St Thomas's Hospital Medical School, London SE1 7EH.

\section{Appendix-Questionnaire content}

\section{(i) Prospective group}

The children completed a questionnaire under the supervision of a teacher and confidentiality was ensured by allowing each child to seal the completed questionnaire in an envelope before handing it in. 
Data linkage from year to year was achieved by using the name and date of birth of the children. The questionnaire included items on: (a) age and sex; (b) smoking behaviour, enabling a classification by regularity of smoking and by consumption; (c) respiratory symptoms; (d) behavioural aspects of smoking, i.e. with whom the child smoked and why; (e) smoking habits of parents, siblings, and peer groups; (f) aspects of social behaviour, e.g. out-ofschool activities, part-time employment, sports, and affiliation to clubs and societies; (g) attitudes towards smokers and smoking in general, the health dangers of smoking, aspects of the home environment, peer group influences.

\section{(ii) Parents of prospective group children}

In 1974 the parents' questionnaire included items on: (a) respiratory symptoms of index child; (b) history of child's respiratory illness; (c) assessment by parent of health status of child; (d) family structure; (e) smoking habits of parents and other members of household; (f) social class (Registrar-General's classification by occupation); (g) attitudinal data, both towards smoking and issues concerning children's behaviour.

\section{(iii) Teachers' questionnaire}

A short anonymous questionnaire recorded the age, sex, smoking habits, and length of employment at the school.

\section{(iv) Secular trend group}

The children completed a shortened version of the prospective group questionnaire, on smoking habits and respiratory symptoms only.

\section{(v) School characteristics}

In addition to questionnaire data from individuals. certain items of information about the schools have been recorded: (a) type of school (grammar, comprehensive, secondary modern, middle); (b) size (small $<400$ pupils, medium 401-600, large 601-1000. very large $>1000$ ); (c) catchment area (mainly urban, suburban, mainly rural, mixed, mining); (d) method of class formation (streaming by ability, nonstreaming, grouped according to subject sets); (e) health education (whether the study year children have health education; if so, what kind it is); (f) staff turnover (ratio of staff leaving to staff remaining per year); (g) delinquency (number of first court appearances per 100 pupils per year); (h) per cent attendance rates; (i) per cent free school meals; (j) smoking by headteacher; (k) school disciplinary policy on smoking; (l) number entered for public examinations.

Copies of the questionnaires can be obtained from the authors. 